\title{
Pictorial representation of idioms in Internet humour
}

\author{
Tomasz Piekot
}

\begin{abstract}
The analysis of new media, especially the Internet, is a serious problem for logocentric communication studies. Usually, only the verbal aspect of genres is described, while other qualities are seen as marginal phenomena. In this paper I want to discuss the practice of visualising idioms in Internet humour. Even a cursory glance at the new media shows two prominent trends: 1) idioms appear in various types of new media texts but tend to dominate in those with a creative function, 2) idioms are spontaneously visualised, i.e. communication partners translate them into visual language. The paper presents results of empirical studies performed on a corpus of demotivators containing idioms. It shows that creative texts, especially humorous ones, subject idioms to different visual transformations. Visual translation may involve the structure of an idiom (individual words) making the visualisation literal, or its metaphoric meaning, in which case the visualisation is figurative (in its two variants - exemplifying or reinterpreting). From the cultural perspective, is it notable that idioms are not very frequent in Internet humour. Demotivators cited idioms in only $1.5 \%$ of all demotivating messages in Polish-language Internet. It seems that Internet users have probably found other visual carriers of figurative meaning. Discovering their social status might be the key to understanding the new culture - the culture of the web.
\end{abstract}

Keywords: idiom, Internet culture, humour, demotivators, visualisation

\section{Introduction}

Seen from the anthropological perspective, human communication is a tool for sustaining and consolidating culture. A linguist who wants to study culture through the prism of language is mostly interested in stable, routine and recurring phenomena. It is by means of such phenomena that language users and co-creators of culture code create and preserve the essence of their collective 
identity, be it in the form of the collective way of perceiving and interpreting reality, the axiological system, or other similar aspects. Information about a particular culture and its features may be found on different levels of communication. It can be retrieved from the grammatical system (e.g. grammatical categories, word formation patterns, sentence patterns), but also from nongrammatical phenomena such as genre patterns, argumentative patterns as well as even everyday metaphors and proverbs (Bartmiński 2009).

One such group of historically preserved repositories of knowledge are idioms understood as conventionalised figurative expressions (multi-expressions). Idioms have acquired high status in many cultures, a fact proved by various social practices. They are very often collected and described in separate dictionaries and are usually incorporated into curricula at schools as well as language and culture courses for foreigners. Idioms are also modified and reinterpreted in the process of creative communication in advertisements, art, and journalistic texts (e.g. newspaper headlines).

The cultural importance attached to idioms also stems from the way civilisation has been evolving. For centuries, the development of civilisation was dominated by logocentrism as language prevailed over other forms of communication and shaped the subsequent stages in cultural evolution - from the oral culture to writing and from print to audiovisual culture (Ong 2002; Hopfinger 2003).

In this context, we may ask the following: What is the future of traditional carriers of cultural knowledge (such aslanguage) when the cultural paradigm changes? Will language cease to be a repository of culture once it loses the status of a dominant code? Will the end of logocentrism and the word-centred culture change the cultural value of metaphors, folklore, proverbs and phraseology?

We may say that the change happens right before our eyes. The culture of the word (logos) is being replaced by the culture of the web ${ }^{1}$ which entails new phenomena and social practices. The most important of these are:

- Dominant role of new technologies (new media) in communication (Manovich 2001);

- Emergence of virtual and Internet communities as well as a new Internet identity (Castells 2000);

- Communication by means of many senses (multisensory communication, virtual reality) and codes (multisemiotic communication) (Camurri \& Rikakis 2004);

- Rapid growth of the semiosphere (signification of human environment);

\footnotetext{
${ }^{1}$ In the literature, there are many symbolic names for the new paradigm: Cyberculture, Web Culture, Culture 2.0, Internet Culture, etc.
} 
- Building a knowledge-based society where the perception of reality is being replaced by perception of information about reality (McLuhan \& Powers 1989; McLuhan 2011; Baudrillard 1994).

As the cultural paradigm changes, it is interesting to observe what happens to traditional carriers of cultural content representing the fading paradigm. It might be especially useful to examine the way language functions in the new media, a hostile semiotic environment preferring other semiotic codes than language. This paper will make observations on this. It will take a closer look at what happens to idioms in Internet humour ${ }^{2}$.

Even a cursory glance at the new media shows two prominent trends which can serve as our point of departure for further analysis:

1. Idioms appear in various types of new-media texts but tend to dominate in those with a creative function which is especially relevant in the case of Internet humour;

2. Idioms are spontaneously visualised, i.e. communication participants translate them into a visual language.

The latter phenomenon whereby idioms are spontaneously transformed into digital images seems especially interesting because of the common nature of the practice (Manovich 2008). Widespread visualisation (or, in a broader sense, using other semiotic codes) marks the difference between Internet culture and the traditional one where visual communication was limited to art and was in this way elitist and exclusive (e.g. satirical cartoons, concrete poetry ${ }^{3}$, etc.).

I want to discuss the practice of visualising idioms in more detail by focusing on one genre - demotivators. The choice is driven by the fact that demotivators are one of the most popular internet genres and are thus useful from the perspective of theoretical considerations. As it has been mentioned above, intentional transformation of idioms is characteristic for creative texts or such messages which are created as artistic (e.g. poetry), persuasive (advertisements, newspaper headlines) and ludic (e.g. jokes) forms of communication. Hence, demotivators are an ideal subject because they perform all those functions - at times they can be entertaining, at times reflexive, philosophical and edifying. They are used very often in political debates. Their form is highly conventionalised and the genre rules are such that the final surprise is the result of the image and words interacting with each other.

\footnotetext{
${ }^{2}$ Internet humour in this context is defined as humorous texts on the Internet, forming a set of genres (types of texts) used only in Internet communication. Internet humour as a type of humour is determined by features of Internet/web culture (see section: The culture of the web and demotivators, below).

${ }^{\mathbf{3}}$ Concrete poetry is a type of poetry in which the typographical arrangement of words is as important in conveying the intended effect as the conventional elements of the poem, such as meaning of words, rhythm, rhyme and so on.
} 
We should also bear in mind that the Internet is in this case the most representative source of empirical data. It is the main social space for a new type of culture and communication which is multisemiotic, integrates multisensory experiences, combines a number of codes, and, most importantly, is possible due to new technologies.

For conceptualising the idiom, the approach of Fernando and Flavell (1981: 17) is adopted in this article. According to them, an idiom is a construction of words relying on two basic conditions: (1) the meaning of an idiom is not the result of the compositional function of its constituents, and (2) an idiom is a unit that either has a homonymous literal counterpart or at least individual constituents that are literal, though the expression as a whole would not be interpreted literally. In the approach suggested here, idioms are complex expressions instead of simple and indivisible language units (in a lexicon) as is the case in generative linguistics. The hypothesis about the complex nature of idioms is backed up by corpus linguistics studies as well as studies on the understanding of idioms and figurative thinking (see overview in Wulff 2008). It is also supported by the fact that the structure of idioms is modified in different ways in the act of communication (see adding, subtracting, substituting, contamination) and what is sometimes visualised are single elements taken from an idiomatic expression.

To sum up, the approach to idioms suggested here combines three perspectives - cognitive, anthropologic and multimodal. From the cognitive perspective, idioms are neither single lexical items nor dead metaphors but have more complex meanings that are motivated by conceptual metaphors linking idiomatic phrases with their figurative interpretations (Kovecses \& Szabo 1996; Langlotz 2006). From the anthropologic (cultural) perspective, idioms and phraseology are the means of representing and reproducing culture (Cowie 1998); there is „a whole cloud of culture condensed in a drop of phraseology" (Wierzbicka 2007). And finally, from the multimodal perspective, people have strong conventional images for many idioms (Gibbs \& O'Brien 1990); idioms are often illustrated for different purposes.

\section{The culture of the web and demotivators}

Demotivators are one of the most popular Internet genres today. As the name suggests, they are the opposite of motivational posters designed for use in schools and offices. Their function is to undermine what is common and dominant. In our case this has to do with the opposition towards traditional cultural content or values as well as the ways these are imposed on the public 
(here: motivating office workers by means of persuasive posters). Opposition towards or protest against the dominant culture is the main objective of early cyberculture. This was to create an alternative world, a counterworld (Macek 2004). Although the idea is weaker today, some of its assumptions have survived and may be found on present day Internet. The most important distinctive features of such an Internet identity - partially manifested in demotivators may be broken down into three categories: participants in the culture, attitude towards the mainstream and distinctive textuality. Let us look at each of them in more detail:

With regard to the people participating in it, the Internet culture is:

- democratic - because everyone can participate in it as long as they have access to the Internet (cf. the notion of "e-exclusion");

- anti-elitist - because real-world social status is not transferred to the Internet where symbolic elites are controlled and even attacked. New symbolic elites usually emerge (e.g. bloggers, moderators, etc.);

- community generating - the traditional notion of a social group is useless on the Internet as there is usually no real bond and no physical contact between members of a virtual group. The Internet sees the emergence of communities which are not formed in the real world (e.g. groups of people with suicidal tendencies, parents wrapping babies, fans of games, etc.); also frequent are purely ad-hoc communities formed for short periods of time on one-off basis (flash mobs);

- normative and restrictive - in order to fully participate in the Internet culture, it is not enough to have the technological means of accessing it; the Internet has its own rules (sometimes termed as "Netiquette") which are codified and very restrictive. The rules apply to every Internet user - everyone is scolded for infringing them.

With regard to the attitude towards the mainstream - Internet culture is interactive and reactive. This tendency is most clearly visible in political life - the Internet is dominated either by critical attitudes towards the current government (cyberanarchy) or by minority and opposition groups. A good case in point is the Polish Internet which is becoming more and more right-wing in its politics and opinion articles. The interactive and reactive nature also has to do with fast and frequent references to facts, events and statements presented in the mainstream media (e.g. Internet jokes based on blunders made by stars and politicians, or Internet protests triggered by reports in the mainstream media, see also Baran 2012). 
With regard to features of messages, the culture of the web is characteristic for its:

- digital nature - manifested in messages which are created in a way which blurs the boundary between what is true and false or real and artificial (e.g. in digital photomontages); another blurred boundary is that between the original and a copy (as visible in the crisis of the traditional concept of copyright);

- multimodality - the Internet message remains a text in the semiotic sense but the term has little to do with the logocentric perception of a text as a linguistic or verbal message. Contemporary Internet messages are multimodal, which means they are multisensory; the final stage of Internet evolution will be marked by communication in a purely virtual environment;

- intertextuality - by their very nature, Internet texts constantly refer to other texts with many types of intertextuality at play such as parody, pastiche, travesty and derivations, hypertextuality, etc.

The features of the Internet culture mentioned above are also visible in the genre of demotivators. Each demotivator should, at least in theory, negate some real value present in the dominant culture and should comply with very restrictive genre norms. What is more, demotivators often refer to other texts, including other demotivators, to create cycles. Let us examine the genre in more detail.

Structurally, a demotivator is comprised of four elements, each with an important function: It has usually a black background (frame), which identifies the genre (all demotivators are placed against the black background). The headline (title) is ideally not more than one word in capital letters, and the subject of a demotivator is always a phenomenon with a high positive value in mainstream culture. Demotivator usually includes a photograph (with the rare exception of drawings or films), i.e. a visual element which usually depicts situations in an undermining way or negates the absolute truth of the value mentioned in the headline. Last but not least, the caption, very often in the form of a punch line or sharp rejoinder, explains the meaning of the photograph.

The structure described above is a canonical model. It is currently often modified by changes being most often limited to disregarding the "single word headline" rule. In such demotivators, headlines are expressed as phrases or even sentences. There are also more and more demotivator-like messages where the image is not in conflict with the headline.

Demotivators demotivate because they deprive the receiver of his self-confidence by undermining those assumptions, values and beliefs which are commonly accepted in mainstream culture. Let us consider two specific examples. 
[1]

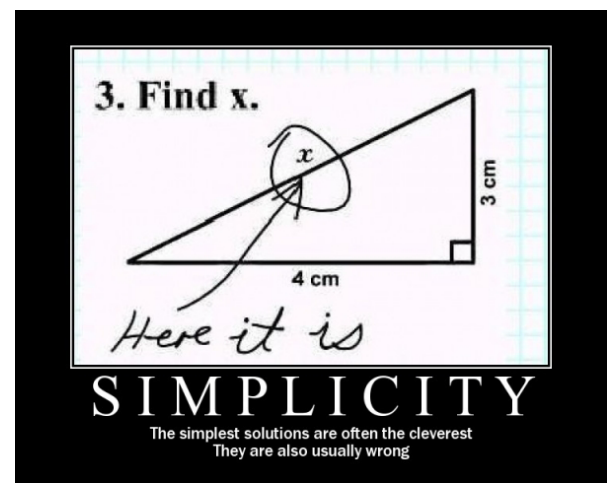

[2]

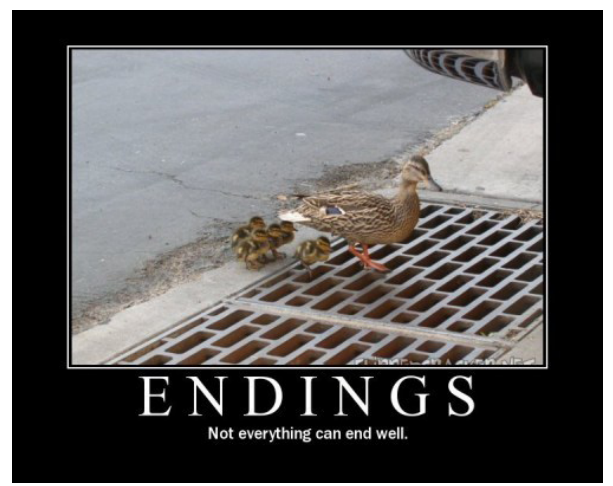

Figure 1. Prototypical demotivators. www.motivateusnot.com.

The first example [1] deals with the category of "simplicity". The cultural value of simplicity is visually undermined by means of a photograph presenting a fragment of a school test or exam. Simplicity - as the punch line says - cannot be good as it is often the result of shrewdness or leads to gross simplifications. The other demotivator [2] uses similar means to undermine the value of a „happy ending”, a very popular myth in Western culture.

\section{Types of idiom visualisations}

We will now concentrate on how idioms are visualised in demotivators. Presented below are the results of empirical studies whose aim was to create a corpus of demotivators containing idioms and then to analyse the way those idioms are visualised. The study was carried out in September 2011 on the basis of 1,000 consecutive demotivators with the highest score on the popular websites $^{4}$ (especially www.demotywatory.pl). The demotivator corpus was supplemented with an additional comparison corpus made up of the best Polish advertising slogans gathered in the collection Stownik sloganów reklamowych. Comparing these two corpora in terms of the idioms they contain allowed me to reach conclusions about the role of idioms in contemporary culture and creative communication. I was especially interested in three questions:

\footnotetext{
${ }^{4}$ Popular demotivators websites usually consist of two sections: The "waiting room" with new demotivators and a "main page" with demotivators selected by Internet users through voting. The corpus consists of 1,000 unique items which were chosen consecutively (without omitting any items) from the page displaying demotivators, ordered by popularity.
} 
1. Is the frequency of idioms in demotivators and advertising slogans high or low?

2. Do the same idioms appear in slogans and demotivators?

3. Are mechanisms of visualising idioms similar in slogans and demotivators?

My first step in the analysis was to compare idioms present in the demotivator corpus with those from the corpus of best Polish advertising slogans. Content analysis showed that idioms are a rarity in both corpora, with slightly more frequent occurrence in advertisements. Best Polish advertising slogans contained 28 idioms from the total 500, which accounts for 5.6\%. In the case of demotivators, the number stood at 15 per 1000 or $1.5 \%$ of the total. Here are some examples ${ }^{5}$ :

\begin{tabular}{|l|l|}
\hline Idioms in advertising slogans & Idioms in demotivators \\
\hline M\&M's - leca w kulki & Odwrócić się do kogoś plecami \\
M\&M's - make you lose your marbles & Turn your back to somebody \\
Fortuna owocem się toczy (Fortuna) & Wpaść w dotek \\
Fruit of fortune (Fortuna) & Be down in the dumps \\
Jesteś w dobrych rękach (Warta) & Mieć niewyparzona gębę \\
You are in good hands (Warta) & Unscalded mouth (to have a biting \\
Ryby maja głos (Lisner) & tongue) \\
Fish have a say (Lisner) & Pracować na czarno \\
Nie drażij lwa (Lion) & Work in the black economy \\
Don't tease the lion (Lion) & Gtodnemu chleb na myśli \\
Nie tam się, przetam się (batonik) & A hungry man will think about bread \\
Don't break down - break to share & Wywrócić coś do góry nogami \\
(chocolate bar) & Turn something upside down \\
Palce lizać (KFC) & \\
Finger lickin' good (KFC) & \\
Red Bull doda ci skrzydet & \\
Red Bull gives you wings & \\
Serce jak dzwon (Kama) & \\
Heart like a bell (Kama) & \\
\hline
\end{tabular}

Interestingly, 11 idioms appeared both in slogans and demotivators so they can be considered to be popular or "powerful". Demotivators also contained 5 winged words from advertisements, i.e. 5 slogans with idioms. Here are a few examples:

${ }^{\mathbf{5}}$ All idioms from these demotivators are well-known in Polish contemporary language. 

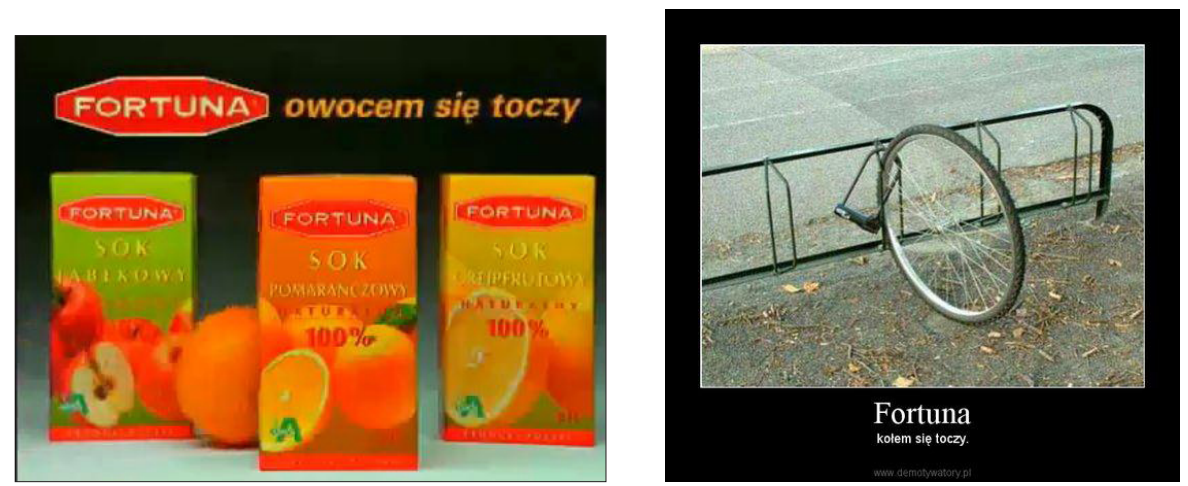

Figure 2. Idiom "wheel of fortune" - 'good luck comes and goes ${ }^{6}$. From www.demotywatory.pl.

Here, the element connecting the two visualisations is the 'wheel' shown literally in the demotivator and figuratively (as a round fruit) in the advertisement. What is different is the way the other element in the idiom, i.e. fortune/luck, is used. In the advertisement [3], "Fortuna" ('fortune') is simply the name of the juice; in the demotivator [4], fortune is lady luck who did not smile on the owner of the bicycle.

[5]

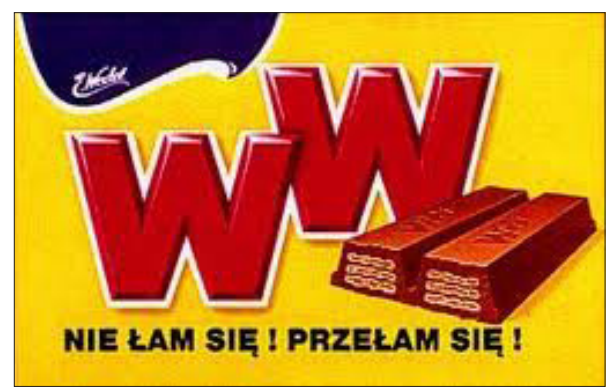

[6]

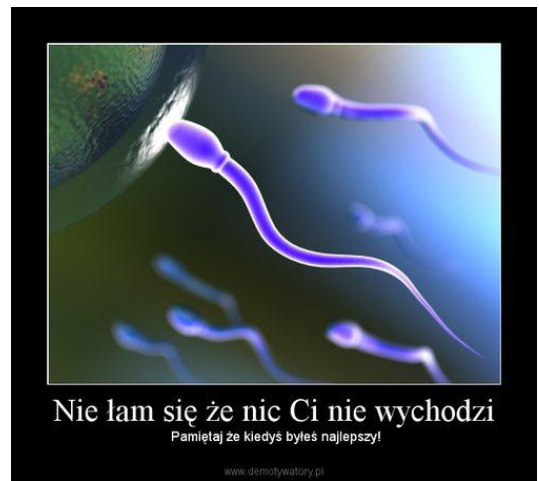

Figure 3. Idiom: "don't break down" - 'don't worry'. Demotivator from: www.demotywatory.pl.

Here, the idiom "don't break down" ('don't worry') performs the same speech act as in the case of the advertisement - it consoles. However, the function is performed in two different ways. In the advertisement [5], the idiom is dem${ }^{6}$ In whole paper, the following marking is used: " " for signifying idioms, and " for their
meaning. 
etaphorised. We can see a broken chocolate bar which is supposed to boost your mood. In the demotivator [6] the person who broke down is consoled by recalling his allegedly greatest success in the caption: "Once, as a single sperm, each one of us won the great race for life".

One of the most popular advertising slogans containing idioms is "It will turn out OK with Kasia" where "Kasia" is a female name and a commercial name for margarine.

[7]

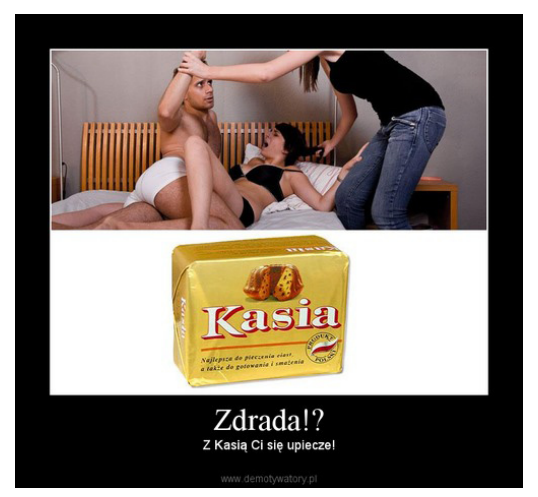

[8]

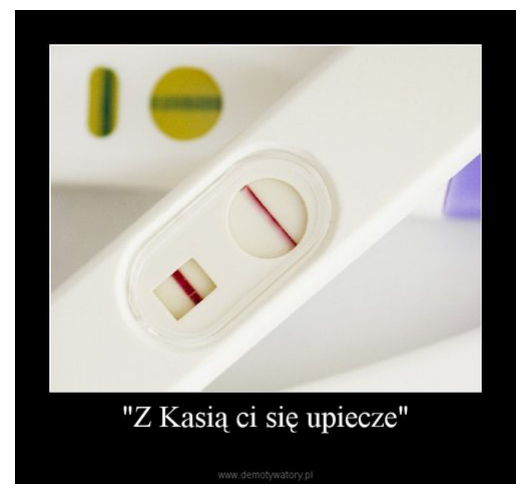

Figure 4. Idiom: "turn out $O K$ / get away with something". From www.demotywatory.pl.

The original advertisement personifies margarine (margarine becomes a woman by the name of Kasia) and demetaphorises the idiom (cakes do in fact turn out tasty when baked with margarine). As we can see, the idiomatic element of guilt or transgression is not present in the original ad. The situation is different in the two demotivators which restore the original figurative meaning. "Kasia" is a woman too, but the reference is to getting away without facing the consequences of illicit sex with Kasia, such as the spouse knowing (7) or pregnancy (8).

To sum up, it seems that the way idioms are used in advertisements is different from their use in demotivators. In advertisements, idioms are often treated instrumentally, hence their frequent demetaphorisation and loss of figurative meaning. The aim of this persuasive trick is mainly to attract attention. Then the values or feelings associated with original idioms are imposed onto the product being advertised, e.g. happiness is attributed to juice ("fruit of fortune"), relief and joy to expected cake ("It will turn out OK with Kasia"). Of course, demetaphorisation is also present in demotivators, but in their case the image often plays the additional role of illustrating or exemplifying the idiom which is treated as a source of knowledge about the world. 
Following a detailed analysis of idiomatic demotivators, we can suggest a typology of mechanisms whereby idioms are visualised (see Fig. 5 below). We must not forget, however, that there are situations where the idiom is totally unrelated to the image. In such cases, visualisation naturally does not take place.

In the group of demotivators in which the image visualises the idiom, we can distinguish literal, figurative and mixed visualisations. Literal visualisation is when at least one of the idiom elements is represented visually (e.g. a photograph of a wheel in 'wheel of fortune'). Figurative visualisation, on the other hand, takes place when a demotivator contains a visual representation of the figurative meaning of the idiom instead of its literal elements. Additionally, figurative visualisation can be broken down into exemplification of the idiomatic meaning and its reinterpretation. In the former case, the meaning of the idiom does not change, whereas in the latter it is modified (including a change in the sphere of values).

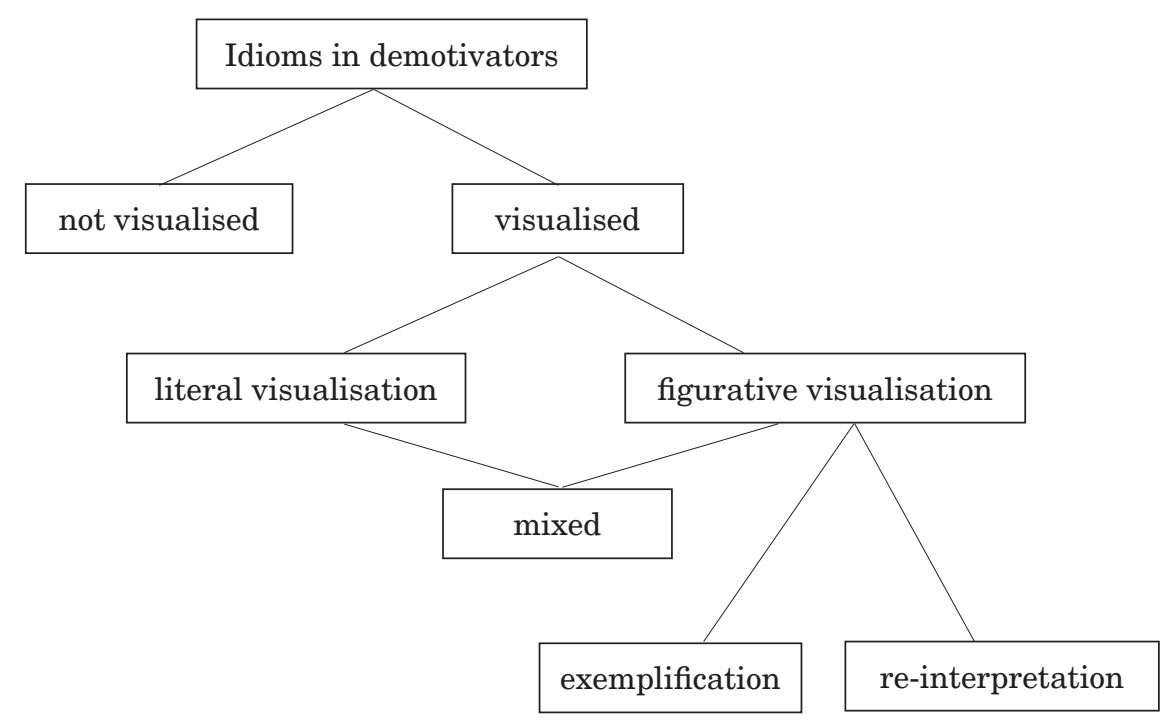

Figure 5. Typology of visual representation of idioms.

This typology should be described in detail. One of the most popular idioms appearing in demotivators is "don't tease the Lion". The expression is visualised in two ways - literally and figuratively. Examples [9] and [10] represent literal visualisations, each of them depicting a 'lion' in a direct or metonymic fashion (claw marks). Example [11] represents figurative visualisation as the image does not contain any structural components of the idiom (i.e. there is neither a lion present nor the action of teasing someone or something). 

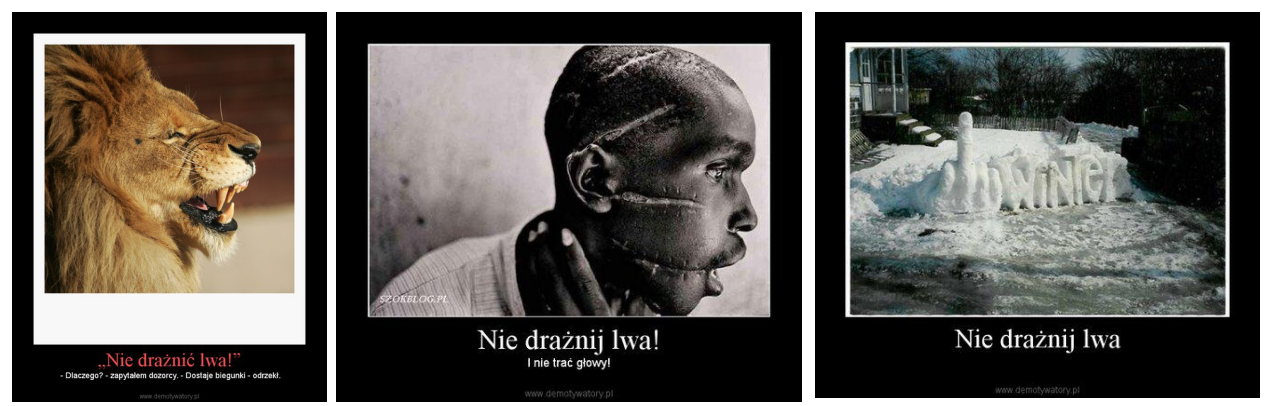

Figure 6. Idiom: "don't tease the Lion”. From: www.demotywatory.pl.

The following three examples show literal visualisations (Figure 7). Example [12] (idiom "unscalded mouth" meaning 'someone having a biting tongue') contains visual representations of as many as two components: 'open mouth' and 'scalding' in the sense of pouring hot water on something. Example [13] (the idiom: "let someone get on top of you") shows the literal action of 'getting on top', and example [14] ("leave with a receipt", meaning 'go away empty-handed') visualises both the word "leave" (solemn way to refer to death) and the word "receipt" (here: a tag).

[12]

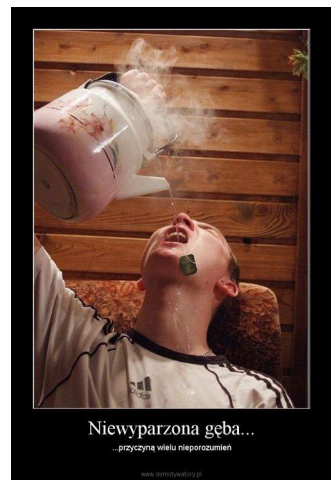

[13]

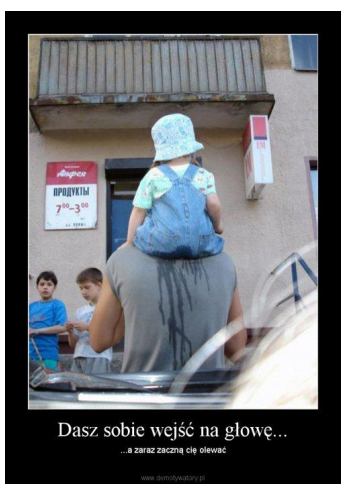

[14]

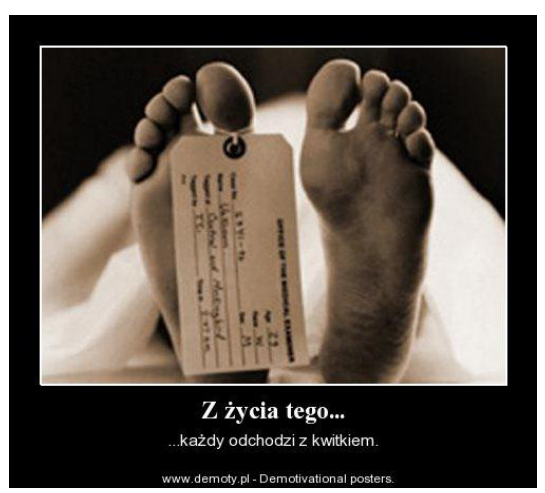

Figure 7. Visual representation of the literal component of idioms. From: www.demotywatory.pl.

What is interesting, literal visualisations are not limited to just one component of an idiom. It is not uncommon to have representations visualising the entire structure of the idiom as is the case in example [15] (idiom: "walls have ears") and example [16] (idiom: "to have a snake in one's pocket" meaning 'to be tight-fisted'): 
[15]

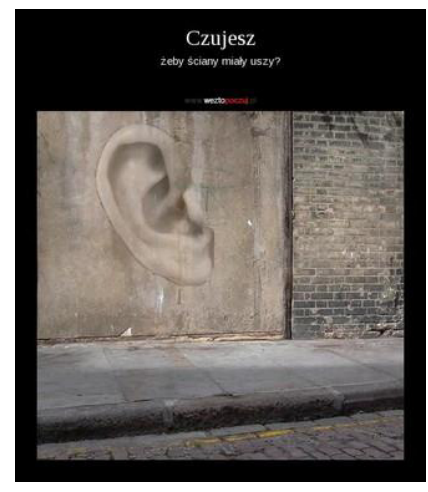

[16]

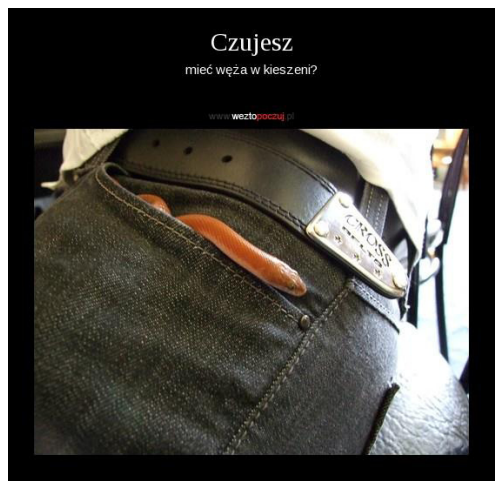

Figure 8. Visual representation of the entire structure of idiom. From: www.demotywatory.pl.

Let us move on to figurative visualisation of idioms (Figure 9, see next page). Such images do not represent words from idioms but from their figurative meanings. Table 1 below sums up the detailed analysis of the three examples:

\begin{tabular}{|l|l|l|l|}
\hline Item & Idiom & Meaning & What can be seen? \\
\hline $\mathbf{1 7}$ & $\begin{array}{l}\text { A hungry man will } \\
\text { think about bread }\end{array}$ & $\begin{array}{l}\text { Those who think } \\
\text { about sex will see sex } \\
\text { everywhere }\end{array}$ & "carrot sex" \\
\hline $\mathbf{1 8}$ & $\begin{array}{l}\text { Between the hammer } \\
\text { and the anvil ("between } \\
\text { a rock and a hard } \\
\text { place") }\end{array}$ & $\begin{array}{l}\text { Be in a tight spot, faced } \\
\text { with two undesirable } \\
\text { alternatives }\end{array}$ & $\begin{array}{l}\text { "Poland between Hitler } \\
\text { and Stalin" }\end{array}$ \\
\hline $\mathbf{1 9}$ & $\begin{array}{l}\text { Necessity is the mother } \\
\text { of invention }\end{array}$ & $\begin{array}{l}\text { We invent things when } \\
\text { we need them }\end{array}$ & $\begin{array}{l}\text { "no hot water" } \\
\text { "electric kettle as } \\
\text { water heater" }\end{array}$ \\
\hline
\end{tabular}

Table 1. Comparative analysis of the demotivators [17], [18] and [19].

Example [20] is slightly different. Here, the meaning of the idiom is reinterpreted. After all "remember something from A to Z" means 'remember something very well'. In this particular demotivator, however, good memory is not positive but negative ('not remembering a party is proof of its success').

Finally, there is mixed visualisation which combines literal and figurative representations. This is clearly visible in examples [21] and [22] (Figure 10). On the one hand, the demotivators represent verbal components of idioms: "horse play" (photograph of a horse) and "do it with your eyes closed" (we can 


\section{Tomasz Piekot}

[17]

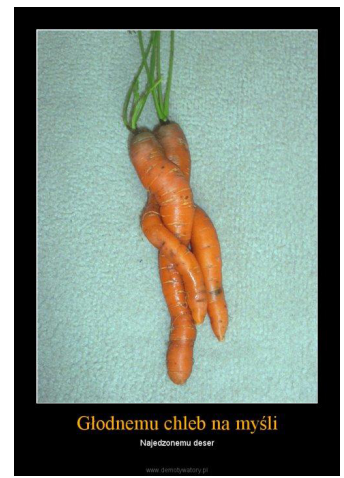

[19]

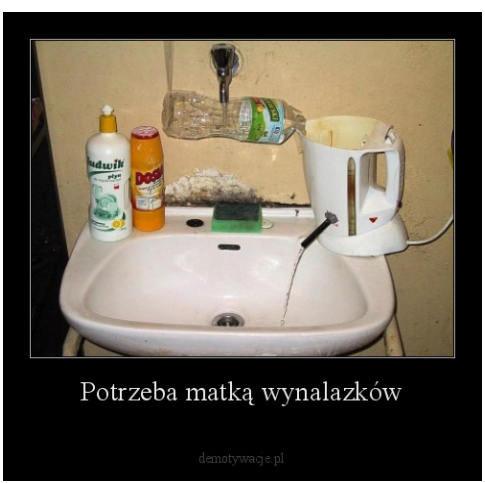

[18]

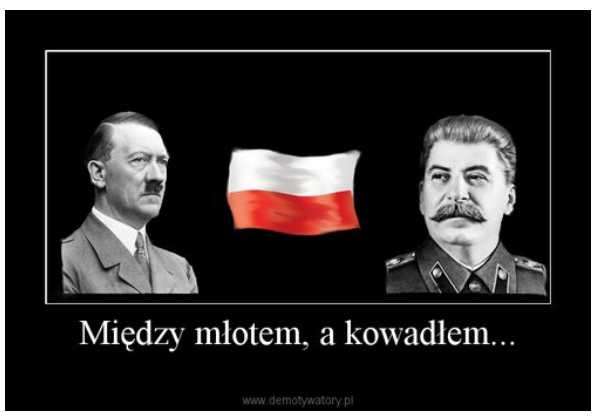

[20]

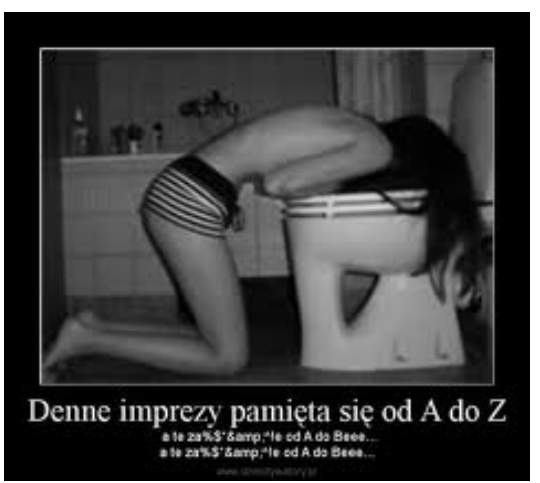

Figure 9. Figurative representations of idiom. From: www.demotywatory.pl.

[21]

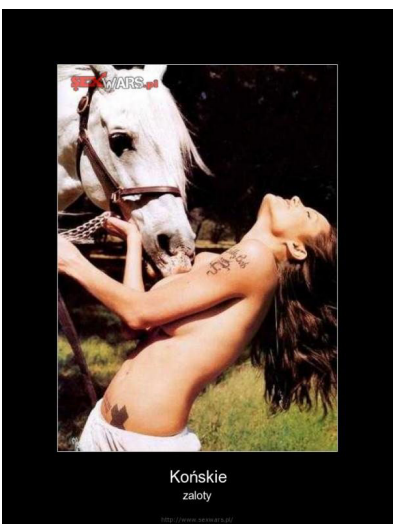

$[22]$

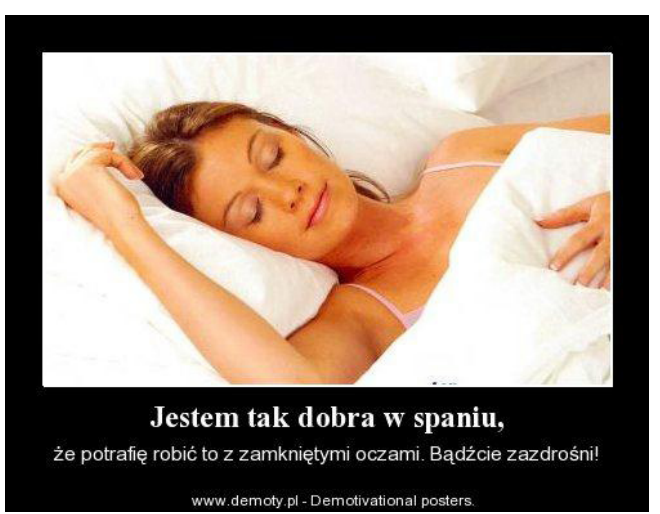

Figure 10. Mixed visualisation of idiom (literal and figurative). From: www.demotywatory.pl. 
see 'closed eyes'); on the other, both demotivators illustrate figurative meanings, i.e. "crude flirting" (here: flirting with an animal) and "being good at something" (here: at sleeping).

\section{Conclusions}

The typology following from empirical studies shows that creative texts, especially the humorous ones, subject idioms to different visual transformations. Intersemiotic translation may involve the structure of an idiom (individual words) making the visualisation literal, or its figurative meaning, in which case the visualisation is figurative (in its two variants - exemplifying or reinterpreting). The presence of two different ways of visualising idioms leads to two basic conclusions: First, idioms are not limited to language. Each idiom has its own mental representation which can be expressed in different semiotic codes. Secondly, idioms may be cognitively represented in two different ways: literal and figurative.

From the cultural perspective it is notable that idioms are not a popular subject in Internet humour. Demotivators using idioms accounted for only $1.5 \%$ of all demotivating messages. We may suspect that the percentage is equally low in the case of every other Internet genre. This is mainly caused by multisemioticity of Internet communication.

As the Internet culture is dominated by images, idioms cease to be treated as convenient carriers of cultural content. Internet users are so used to visual communication that they have probably found other visual carriers which are similarly conventional and figurative but show more ludic potential. If we were to identify one visual phenomenon which most resembles idiomatic phrases, these would probably be Internet memes. Such memes share at least five characteristics with idioms: conventionality, figurative nature, reproducibility (they are copied in many contexts), considerable potential for creative and humorous transformations and, finally, preservation of content which is important for a given culture or social group. The study on Internet memes - the most recent web-based phenomenon adopted from scientific research (Dawkins 1976; Blackmore 2000; Aunger 2002) - is arguably the biggest challenge faced by today's research in the humanities. Discovering their communication and cultural status might be the key to understanding the new culture - the culture of the web. 


\section{Tomasz Piekot}

\section{Acknowledgement}

Project was funded by the Polish National Science Center.

\section{References}

Aunger, Robert 2002. The electric meme: A new theory of how we think. New York: Free Press.

Baran, Anneli 2012. Visual humour on the Internet. In: L. Laineste \& D. Brzozowska \& W. Chłopicki (eds.) Estonia and Poland: Creativity and tradition in cultural communication, Vol 1. Tartu: ELM Scholarly Press, pp. 171-186.

Bartmiński, Jerzy 2009. Aspects of cognitive ethnolinguistics. London: Equinox.

Baudrillard, Jean 1994. Simulacra and simulation. Ann Arbor: University of Michigan Press.

Blackmore, Susan J. 2000. The meme machine. Oxford: Oxford UP.

Camurri, Antonioj \& Rikakis, Thanassis 2004. Guest editors' introduction: Multisensory communication and experience through multimedia. IEEE Multimedia, Vol. 11, No. 3, pp. 17-19.

Castells, Manuel 2000. The rise of the network society. London: Blackwell Publishers.

Cowie, Anthony Paul (ed.) 1998. Phraseology: theory, analysis and applications. Oxford: Clarendon Press.

Dawkins, Richard 1976. The selfish gene. Oxford: Oxford UP.

Fernando, Chitra \& Flavell, Roger 1981. On idiom: Critical views and perspectives. Exeter Linguistic Studies, Vol. 5. Exeter: University of Exeter.

Gibbs, Raymond W. \& O’Brien, Jennifer E. 1990. Idioms and mental imagery: The metaphorical motivation for idiomatic meaning. Cognition, Vol 36, No. 1, pp. 35-68.

Hopfinger, Maryla 2003. Doświadczenia audiowizualne. O mediach $w$ kulturze wspótczesnej. [Audiovisual experiences. Media in contemporary culture.] Warszawa: Sic.

Kovecses, Zoltan \& Szabo, Peter 1996. Idioms: A view from cognitive semantics. Applied Linguistics, Vol. 17, No. 3, pp. 326-355. 
Langlotz, Andreas 2006. Idiomatic creativity: A cognitive linguistic model of idiom-representations and idiom-variation in English. Amsterdam and Phildelphia: John Benjamins.

Macek, Jakub 2004. Defining cyberculture. In: P. Binková \& J. Volek (eds.) Média a realita. Brno: Masaryk University Press, pp. 35-65. http://macek.czechian.net/defining_cyberculture.htm, last accessed on 19 May 2012.

Manovich, Lev 2001. The language of new media. Cambridge: The MIT Press.

Manovich, Lev 2008. The practice of everyday (media) life: From mass consumption to mass cultural production? Critical Inquiry, Vol. 35, No. 2, pp. 319-331.

McLuhan, Marshall \& Powers, Bruce R. 1989. The global village: Transformations in world life and media in the 21st century. Oxford: Oxford UP.

McLuhan, Marshall 2011. Gutenberg galaxy: The making of typographic man. Toronto: University of Toronto Press.

Ong, Walter 2002. Orality and literacy: The technologizing of the word (2nd ed.). New York: Routledge.

Spychalska, Marta \& Hołota, Marcin 2009. Stownik sloganów reklamowych. [A dictionary of advertising slogans.] Warszawa: Wydawnictwo Naukowe PWN.

Wierzbicka, Anna 2007. Reasonably well: Natural semantic metalanguage as a tool for the study of phraseology and of its cultural underpinnings. In: P. Skandera (ed.) Phraseology and culture in English. Berlin: Mouton de Gruyter, pp. 49-78.

Wulff, Stefanie 2009. Rethinking idiomaticity: A usage-based approach. London/New York: Continuum. 


\section{Tomasz Piekot}

\section{Internet sources}

http://demotywatory.pl/, last accessed on 19 May 2012.

http://demotywatory.net/, last accessed on 19 May 2012.

http://www.sexwars.pl/, last accessed on 19 May 2012.

http://www.motivateusnot.com, last accessed on 19 May 2012. 